\title{
Characteristics associated with organic food consumption during pregnancy; data from a large cohort of pregnant women in Norway
}

Hanne Torjusen ${ }^{1,2^{*}}$, Anne Lise Brantsæter ${ }^{1}$, Margaretha Haugen', Geir Lieblein ${ }^{3}$, Hein Stigum ${ }^{4}$, Gun Roos $^{2}$, Gerd Holmboe-Ottesen ${ }^{5}$, Helle Margrete Meltzer ${ }^{1}$

\begin{abstract}
Background: Little is known about the use of organic food during pregnancy. The aim of this study was to describe characteristics associated with the use of organic food among pregnant women participating in the Norwegian Mother and Child Cohort Study (MoBa).

Methods: The present study includes 63,561 women who during the years 2002-2007 answered two questionnaires, a general health questionnaire at gestational week 15 and a food frequency questionnaire at weeks 17-22. We used linear binomial regression with frequent versus rare use of organic food as outcome variable and characteristics of the respondent as independent variables. The outcome variable was derived from self-reported frequency of organic food use in six main food groups (milk/dairy, bread/cereal, eggs, vegetables, fruit and meat).

Results: Organic eggs and vegetables were the food items which were most frequently reported to be used "often" or "mostly". The proportion of women reporting frequent intake of organic food was $9.1 \%(n=5754)$. This group included more women in the lower ( $<25$ years) and higher ( $>40$ years) age-groups, with normal or low body mass index, who were vegetarians, exercised regularly (3+times weekly), consumed alcohol and smoked cigarettes during pregnancy ( $<0.001$ for all, except alcohol: $p=0.044)$. Further, participants with frequent organic consumption included more women in the lower ( $\leq 12$ years) or higher (17 years + ) category of educational attainment, women who were students or had a partner being a student, who belonged to the lowest household income group (both respondent and her partner earned <300 000 NOK), who entered the study 2005-2007, and who lived in an urban area $(p<0.001$ for all).

Conclusions: The socio-economic characteristics of pregnant Norwegian women with frequent organic consumption did not unambiguously follow those typically associated with better health, such as higher levels of education and income. Rather, lower household income, and both lowest and highest levels of education were associated with a higher prevalence of frequent organic consumption. The results indicate that personal and socioeconomic characteristics are important covariates and need to be included in future studies of potential health outcomes related to organic food consumption during pregnancy.
\end{abstract}

\section{Background}

Dietary quality is especially critical during pregnancy, as adequate nutrition is essential for both maternal and foetal health. There is growing evidence that maternal diet may influence longer-term health of the offspring

\footnotetext{
* Correspondence: hanne.torjusen@sifo.no

'Division of Environmental Medicine, Norwegian Institute of Public Health, Oslo, Norway

Full list of author information is available at the end of the article
}

even within relatively well-nourished populations [1-3]. Dietary intake and food patterns have been described among pregnant women in many populations including Norway [4-6], but little is known about pregnant women who go against mainstream food culture and choose to eat vegetarian diets or organically grown food. In Norway, the generic term for 'organic food' includes food produced at farms following the basic certification requirements as well as farms practicing biological

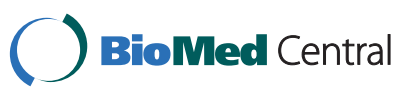


dynamic agriculture. Debio is the Norwegian certification body administering the label ' $\varnothing$ ' for organic food, which is combined with the international label 'Demeter' in the case of bio-dynamic food [7]. The interest for and reported use of organically grown food in the diet has increased in the general public in Norway during the last decade, with women reporting a higher interest than men (25\%, as compared to $16 \%$ ) [8]. It is known from a number of previous studies that health is a main motivation for choosing organic food $[9,10]$. The expected beneficial health effects of eating organic food during pregnancy include avoiding the possible risks of exposing the developing foetus to synthetic pesticides [11]. On the other hand, higher risks of contamination from mycotoxins, heavy metals and enteric pathogens that could complicate pregnancy have frequently been ascribed to organic production methods, although studies have shown less fusarium mycotoxin contamination $[12,13]$ and lower risk of salmonella and E. coli $[14,15]$ in organic than in conventional foods. Furthermore, higher levels of beneficial substances such as bioactive compounds in plant foods [16,17] and polyunsaturated fatty acids, such as omega-3 and CLA [18] in milk - also found in higher levels in breast milk of lactating women who had eaten organic dairy and/or meat products [19] may be associated with health benefits. A review of literature published in the period from 1958 to 2008 concluded, based on 55 studies, that there is no evidence of a difference in nutrient quality between organically and conventionally produced foodstuffs of relevance to health [20]. Another review by the same authors concluded, based on 12 studies from the same time period, that there is currently no evidence of a health benefit from consuming organic compared to conventionally produced foodstuffs [21]. While the first of these reviews has been criticised for omitting relevant research due to inaccurate selection criteria [22], there seem to be consensus that there is need for further and more detailed studies to investigate possible health effects of eating organic food.

The possible associations between eating organic food and other lifestyle factors and health behavior are not well-described. Information about the prevalence of use of organically grown food within sub-groups of the population is lacking. Such knowledge is important to obtain, especially in critical life phases such as pregnancy, as maternal diet, and possibly also organic food consumption, may have long-term implications for health of the offspring $[1,2]$. Very few investigations have been conducted concerning the health effects or safety of organic food and no studies have evaluated this in a pregnant human population. The Norwegian Mother and Child Cohort Study (MoBa), a nation wide prospective pregnancy cohort that since 2002 has asked pregnant women about their frequency of organic food use, provides a unique possibility to explore background characteristics and lifestyle behaviors associated with the consumption of organic food during pregnancy. In $\mathrm{MoBa}$ we also plan to investigate dietary habits among organic food consumers and to examine potential diethealth relationships related to organic food consumption during pregnancy. To the best of our knowledge, this is the first study to report the use of organic food among pregnant women in relation to a wide range of personal and socio-demographic characteristics.

Compared to other European countries, the development of the organic food market in Norway has been slow [23] and for several decades, organic food had a marginal position outside of the conventional food market [24]. During the last 10-15 years, however, organic products have slowly been introduced into the Norwegian general food market, and sales have grown rapidly in the last few years parallel with an increase in the number of food items certified as organic, particularly since 2005 [25].

Given the close relation between consumers' choice of organic food and their focus on health, as well as the particular relevance of health during pregnancy, the aim of this study was to examine associations between frequent consumption of organic food during pregnancy and health behaviors, socio-economic and demographic characteristics. Could it be that women eating organic food during pregnancy live particularly healthy? Or, on the other hand, could it be that the choice of organic food during pregnancy is associated with lifestyle patterns which are contrary to public advice and knowledge about diet and health relationships?

\section{Methods}

\section{Subjects and Methods}

The data set is part of the MoBa study, initiated by and maintained at the Norwegian Institute of Public Health, and this study is presently the largest pregnancy cohort in the world with 107000 pregnancies included since 1999 [26]. Pregnant women were recruited to the study by postal invitation after they had signed up for the routine ultrasound examination in their local hospital. The participation rate was about $43 \%$ [26]. The women were asked to provide biological samples and to answer questionnaires covering a wide range of information. The cohort database is linked to the Medical Birth Registry of Norway and other national health registries. The MoBa study has been approved by the Regional Committee for Ethics in Medical Research and the Data Inspectorate in Norway.

\section{Subjects}

This study uses version 4 of the data files made available for research in January 2009. To be included in the 
present study, the women had to have responded to the general questionnaire at gestational week 15 and to the MoBa food frequency questionnaire (FFQ) at weeks 17-22. In addition, participants had to have answered at least one of the 6 questions about organic food, and have a reported daily energy intake $>4.5 \mathrm{MJ}$ or $<20 \mathrm{MJ}$ [27]. We only used data from the first time participation for women who had been included in the MoBa more than once because of multiple pregnancies. This resulted in a sample of 63,808 women. From this sample, we excluded 250 women who had missing values on age $(\mathrm{n}=4)$ or urban/rural living $(\mathrm{n}=246)$ due to the small numbers, resulting in a final study sample of 63,561.

\section{The MoBa food frequency questionnaire}

The MoBa FFQ http://www.fhi.no/dokumenter/011fbd699d. pdf is a semi-quantitative food frequency questionnaire designed specifically for assessing diet during the first four months of pregnancy, when the fetus is most vulnerable [3]. The FFQ is described in detail elsewhere [27]. Data has been collected from February 2002 and onwards. The questionnaire has 40 categories of questions covering the daily intake of 255 specific food items and dietary profile such as vegetarian, vegan or partly vegetarian and use of organic food in six main food groups (milk/dairy, bread/cereal, eggs, vegetables, fruit and meat).

\section{Outcome variable}

The use of organic food was calculated as a sum index based on the question about the frequency of use of organic food specified in six food groups: milk and dairy products, bread and cereal products, eggs, vegetables, fruit and meat. The alternative answers for use of organic food were: 'never or seldom', 'sometimes', 'often', or 'mostly' and were given values from 0 -3. For those who had answered at least one of the questions about organic food, missing values for one or more of the other questions were interpreted as 'seldom or never'. The sum index reflects organic food consumption on a scale ranging from 0 to 18 , with 0 representing no use of organic food and 18 representing "mostly" organic for all six food groups. Due to inconstancy between the reported dietary profile (vegetarian) and food intakes in the FFQ, we defined 'vegetarian' as having no intake of meat and fish based on the actual food intake. All respondents reported consumption of bread/ cereal products and fruit. However, for respondents who had no reported intake of meat $(\mathrm{n}=361)$, eggs $(\mathrm{n}=$ $1462)$, milk/dairy $(\mathrm{n}=718)$ or vegetables $(7)$ and who had not reported organic consumption of the corresponding food group, we upscaled the sum index by multiplying with $6 / 5$ for each omitted food category. This resulted in the upscaling of 817 subjects and included not only vegetarians, but also individuals who avoided relevant food groups due to for instance allergy.
We defined frequent organic consumption as having a sum index of $>6$, which corresponds to at least one organic food answer in the "often" category. The upscaling resulted in allocation of 48 respondents into the "frequent organic' consumption group, of which three were vegetarians.

\section{Other variables}

From the MoBa FFQ, we included the following dietary variables: The inclusion of meat or fish in the diet or a vegetarian diet, and alcohol consumption (yes/no). The variable for vegetarian diet in this study comprises vegans, lacto-vegetarians and lacto-ovo-vegetarians.

From the general questionnaire we included the participant's age, pre-pregnancy body mass index (BMI), smoking, exercise, level of education, the participant or her partner being a student, household income, and year of participation in MoBa. Age was divided into six categories $(<20,20-24,25-29,30-34,35-39,40+$ years $)$. BMI was calculated from self-reported height and prepregnant weight and categorized according to the WHO classification as normal $\left(18.5-24.9 \mathrm{~kg} / \mathrm{m}^{2}\right)$, underweight $\left(\leq 18.5 \mathrm{~kg} / \mathrm{m}^{2}\right)$, overweight $\left(25.0-29.9 \mathrm{~kg} / \mathrm{m}^{2}\right)$, obese grade $1\left(30.0-34.9 \mathrm{~kg} / \mathrm{m}^{2}\right)$ or obese grade $2(\geq 35.0 \mathrm{~kg} /$ $\mathrm{m}^{2}$ ). Smoking during pregnancy was divided into three categories (daily smokers, occasional smokers and nonsmokers). Exercise during pregnancy was based on respondents' reports of their participation in 13 different types of recreational exercise and divided into four categories (no exercise, less than once weekly, 1-2 times weekly and 3+ times weekly). Education was divided into three categories: high school or less ( $\leq 12$ years), 3-4 years of college/university (13-16 years) or four or more years of college/university education (17+ years). Being a student (yes/no) was included for both the participant and her partner. Household income was measured as a combination of the participant's and her partner's income (both $<300000 \mathrm{NOK}$, one $\geq 300000$ NOK, or both $\geq 300000 \mathrm{NOK})$. Urban or rural living area was explored using several variables: 1) an urban/ rural variable based on 35 selected urban municipalities with $>20,000$ inhabitants and city status, 2) a variable based on 32 selected rural municipalities with a special focus on organic food, and 3) a variable indicating geographic location of a municipality in relation to urban settlements of various sizes, according to definitions obtained from Statistics Norway [28].

\section{Statistical analyses}

We used polychoric correlation to examine organic consumption among all food groups. The differences in organic food consumption between categories of maternal characteristics were tested using chi-square, and $p$ value of $<0.05$ were considered to indicate statistical significance. We used linear binomial regression, with 
frequent use of organic food (sum index $>6$ ) as the binomial outcome variable. This analysis provides information about the risk difference (RD) between being in the frequent organic intake group or not, given various personal, socio-economic and lifestyle characteristics as covariates. Linear rather than logistic regression was preferred because the risk estimates for various constellations of covariates may be directly interpreted from the adjusted model as prevalence at reference category $+/$ - the risk difference for any given characteristic/covariate, e.g. year 2005, age 35-39 etc. The model was checked by repeating the analysis using linear regression with the sum index as a continuous outcome variable, and comparable results were obtained (not shown).

A total of 13,174 (20.7\%) women had missing values on one or more of the covariates. Participants with missing data on a variable are often categorized in a "missing" category to avoid exclusion of incomplete cases. This may, however, introduce bias. We therefore performed the linear binomial analysis in the full sample $(\mathrm{n}=63,561)$ as well as in complete cases only $(50,387)$ to examine the influence of including incomplete cases. The results were almost identical and we chose to present results for the full sample.

All analyses were performed using the statistical software PASW statistics 17 (SPSS Inc., IBM Company, Chicago, Ill., USA), except the polychoric correlation analysis which was performed in Stata version 11 (Stata Corp, Texas 77845 USA).

\section{Results}

Eggs and vegetables were the food categories that most respondents reported to use 'often' or 'mostly' organic, while few women reported consumption of organic meat. Across all food categories, the 'never/seldom' organic was the dominant answer, ranging from $65.4 \%$ for vegetables to $88.7 \%$ for meat, while the most frequent organic user group was small, ranging from 1.0\% for meat to $3.5 \%$ for eggs. A total of 3376 (6.7\%) women reported 'mostly' organic consumption for at least one of the six food groups (Table 1). There was a high correlation between organic food consumption across the food groups, with vegetables and fruits being most strongly correlated with each other and with the sum index (Table 2).

When summing the reported use of organic food across the six food groups, $1.9 \%$ of the women reached a sum index of 13 to $18,7.2 \%$ had a sum index of 7 to 12 , $39.2 \%$ had a sum index of 1 to 6 and $51.7 \%$ a sum index of 0 , indicating that they had answered never or seldom to all organic food categories. In the further analysis we chose to define frequent organic consumption as having a sum index $>6$, which corresponds to reported consumption of at least one organic food group in the 'often'
Table 1 Self reported organic consumption of six main food categories§.

\begin{tabular}{lllll}
\hline & $\begin{array}{l}\text { 'Never/ } \\
\text { seldom' } \\
\text { (Value 0) } \\
\text { \% answered }\end{array}$ & $\begin{array}{l}\text { 'Sometimes' } \\
\text { (Value 1) } \\
\text { answered }\end{array}$ & $\begin{array}{l}\text { 'Often' } \\
\text { (Value 2) } \\
\text { \% } \\
\text { answered }\end{array}$ & $\begin{array}{l}\text { 'Mostly' } \\
\text { (Value 3) } \\
\text { \% } \\
\text { answered }\end{array}$ \\
\hline Milk/dairy & 74.5 & 18.3 & 4.6 & 2.5 \\
Bread/ & 80.0 & 13.7 & 3.7 & 2.6 \\
cereal & & & & \\
Eggs & 66.2 & 24.2 & 5.7 & 3.4 \\
Vegetables & 65.4 & 27.2 & 5.6 & 1.7 \\
Fruit & 71.7 & 21.7 & 4.7 & 1.8 \\
Meat & 88.0 & 7.8 & 3.1 & 1.1 \\
Any & 92.8 & 44.9 & 13.6 & 7.0
\end{tabular}

${ }^{5}$ Percentage reported use within each food category. $\mathrm{N}=63,561$ pregnant women in the Norwegian Mother and Child Cohort Study 2002-2007

category. This resulted in 5754 (9.1\%) frequent organic consumers (Table 3). There was a strong effect of age on frequent organic food consumption; among 30-34 year old there were $8.1 \%$ frequent consumers, compared to $28 \%$ among $<20$ year old, a crude difference of 20 percentage points (pp). The adjusted difference from the model was $15.6 \mathrm{pp}$ (Table 3$)$.

Higher prevalence of frequent organic use was also found among women in the underweight and normal weight BMI categories. The largest difference in use of organic food was found for eating a vegetarian diet (RD = $23.1 \mathrm{pp}$.), while only a very low share of participants were vegetarians $(0.2 \%)$ (Table 3$)$.

Overall, $91.6 \%$ of the women in this study were non smokers and $88.4 \%$ abandoned alcohol completely during pregnancy. However, among smokers and among women who consumed alcohol during pregnancy, there was a higher prevalence of frequent organic use. Further, physical activity three times a week or more was associated with a higher prevalence of organic food consumption (Table 3).

With regard to education, there was a two-sided trend with more frequent organic food consumption among those with 12 years or less or 17 years or more, while it

Table 2 Polychoric correlation between the reported use of organic food categories ( $n=63,561$ )

\begin{tabular}{|c|c|c|c|c|c|c|c|}
\hline & $\begin{array}{l}\text { Milk/ } \\
\text { dairy }\end{array}$ & $\begin{array}{l}\text { Bread/ } \\
\text { cereal }\end{array}$ & Eggs & Vegetables & Fruits & Meat & $\begin{array}{l}\text { Sum } \\
\text { index }^{\S}\end{array}$ \\
\hline Milk/dairy & 1 & 0.79 & 0.68 & 0.73 & 0.72 & 0.74 & 0.76 \\
\hline $\begin{array}{l}\text { Bread/ } \\
\text { cereal }\end{array}$ & & 1 & 0.65 & 0.75 & 0.79 & 0.81 & 0.78 \\
\hline Eggs & & & 1 & 0.74 & 0.70 & 0.65 & 0.73 \\
\hline Vegetables & & & & 1 & 0.92 & 0.78 & 0.82 \\
\hline Fruit & & & & & 1 & 0.82 & 0.82 \\
\hline Meat & & & & & & 1 & 0.73 \\
\hline
\end{tabular}

${ }^{\S}$ Sum index is the summation of reported use across all food categories 
Table 3 Association between socio-economic, personal and lifestyle factors and frequent consumption of organic food.

\begin{tabular}{|c|c|c|c|c|c|c|}
\hline & & Un & nodel & & & Adjusted model $^{\S}$ \\
\hline & & & ex $>6$ & $P$-value* & $R D^{*} 100$ & $(95 \% \mathrm{Cl})$ \\
\hline & $\begin{array}{l}\text { Total } n \\
63,561\end{array}$ & $\mathrm{n}$ & $\%$ & & & \\
\hline Total & & & 9.1 & & & \\
\hline Prevalence at ref. category & & & & & 7.8 & \\
\hline Age & & & & $<0.001$ & & \\
\hline$<20$ & 854 & 239 & 28 & & 15.6 & $(12.6,18.7)$ \\
\hline $20-24$ & 7745 & 996 & 12.9 & & 3.0 & $(2.1,3.8)$ \\
\hline $25-29$ & 22689 & 1820 & 8.0 & & -0.5 & $(0.9,0.0)$ \\
\hline $30-34$ & 22925 & 1866 & 8.1 & & 0 & \\
\hline $35-39$ & 8306 & 715 & 8.6 & & 0.3 & $(-0.4,0.9)$ \\
\hline $40+$ & 1042 & 118 & 11.3 & & 2.6 & $(0.7,4.5)$ \\
\hline Prepregnant BMI & & & & $<0.001$ & & \\
\hline$<18.5$ & 1825 & 226 & 12.4 & & 1.8 & $(0.4,3.3)$ \\
\hline $18.5-24.9$ & 40519 & 3795 & 9.4 & & 0 & \\
\hline $25-29.9$ & 13547 & 1102 & 8.1 & & -0.9 & $(-1.4,-0.4)$ \\
\hline $30-34.9$ & 4355 & 314 & 7.2 & & -1.8 & $(-2.5,-1.1)$ \\
\hline $35+$ & 1645 & 128 & 7.8 & & -1.5 & $(-2.7,-0.3)$ \\
\hline Missing & 1670 & 189 & 11.3 & & 1.0 & $(-0.5,2.5)$ \\
\hline Dietary habits & & & & $<0.001$ & & \\
\hline Meat/fish & 63449 & 5716 & 9.0 & & 0 & \\
\hline Vegetarian & 112 & 38 & 33.9 & & 23.1 & $(14.4,31.8)$ \\
\hline Alcohol in pregnancy & & & & 0.59 & & \\
\hline No & 56182 & 5072 & 9.0 & & 0 & \\
\hline Yes & 7379 & 682 & 9.2 & & 0.7 & $(0.0,1.4)$ \\
\hline Smoking in pregnancy & & & & $<0.001$ & & \\
\hline No smoking & 58241 & 5116 & 8.8 & & 0 & \\
\hline Occasionally & 1812 & 218 & 12.0 & & 2.0 & $(0.6,3.4)$ \\
\hline Daily & 3508 & 420 & 12.0 & & 1.5 & $(0.5,2.6)$ \\
\hline Exercise in pregnancy & & & & $<0.001$ & & \\
\hline No & 9166 & 756 & 8.2 & & 0 & \\
\hline Less than weekly & 12317 & 888 & 7.2 & & -0.5 & $(-1.1,0.2)$ \\
\hline 1-2 times weekly & 18734 & 1538 & 8.2 & & 0.4 & $(-0.3,1.0)$ \\
\hline 3+ times weekly & 17992 & 1956 & 10.9 & & 2.5 & $(1.8,3.2)$ \\
\hline Missing & 5352 & 616 & 11.5 & & 2.6 & $(1.7,3.6)$ \\
\hline Education & & & & $<0.001$ & & \\
\hline$<10 y-12 y$ & 20398 & 2252 & 11.0 & & 0 & \\
\hline $13-16$ y & 26462 & 1822 & 6.9 & & -2.5 & $(-3.0,-1.9)$ \\
\hline $17+$ & 15319 & 1534 & 10.0 & & -0.1 & $(-0.7,0.6)$ \\
\hline Missing & 1382 & 146 & 10.6 & & -0.2 & $(-1.8,1.4)$ \\
\hline Student, participant & & & & $<0.001$ & & \\
\hline No & 57279 & 4928 & 8.6 & & 0 & \\
\hline Yes & 6282 & 826 & 13.1 & & 1.9 & $(1.1,2.8)$ \\
\hline Student, participant's partner & & & & $<0.001$ & & \\
\hline No & 60296 & 5342 & 8.9 & & 0 & \\
\hline Yes & 3265 & 412 & 12.6 & & 1.7 & $(0.6,2.9)$ \\
\hline Household income & & & & $<0.001$ & & \\
\hline Low (both <NOK 300 000) & 17324 & 1861 & 10.7 & & 0 & \\
\hline Medium (one $\geq$ NOK 300 000) & 24357 & 1947 & 8.0 & & -1.6 & $(-2.1,-1.0)$ \\
\hline High (both $\geq$ NOK 300 000) & 16561 & 1268 & 7.7 & & -2.3 & $(-2.9,-1.6)$ \\
\hline Missing & 5319 & 677 & 12.7 & & 1.0 & $(-0.0,1.9)$ \\
\hline
\end{tabular}


Table 3 Association between socio-economic, personal and lifestyle factors and frequent consumption of organic food. (Continued)

\begin{tabular}{|c|c|c|c|c|c|c|}
\hline Year of participation & & & & $<0.001$ & & \\
\hline 2002 & 8768 & 679 & 7.7 & & 0 & \\
\hline 2003 & 10834 & 855 & 7.9 & & 0.3 & $(-0.4,1.0)$ \\
\hline 2004 & 10717 & 834 & 7.8 & & 0.4 & $(-0.3,1.1)$ \\
\hline 2005 & 12369 & 1135 & 9.2 & & 1.5 & $(0.8,2.2)$ \\
\hline 2006 & 11030 & 1097 & 9.9 & & 2.3 & $(1.6,3.1)$ \\
\hline 2007 & 8562 & 993 & 11.6 & & 4.1 & $(3.3,5.0)$ \\
\hline Missing & 1281 & 161 & 12.6 & & 3.6 & $(1.7,5.4)$ \\
\hline Living area & & & & $<0.001$ & & \\
\hline Rural & 31070 & 2675 & 8.6 & & 0 & \\
\hline Urban & 32491 & 3079 & 9.5 & & 0.6 & $(0.1,1.0)$ \\
\hline
\end{tabular}

$\S$ Linear binomial model. Prevalence at reference category shows the constant term which equals expected use of organic food with medium or high frequency (Sum index $>6$ ) when all covariates are zero.

The table shows risk differences $\times 100$ (with $95 \%$ confidence interval) for frequent consumption of organic food. Zero values are the reference categories.

${ }^{*} \mathrm{P}$ for trend across characteristic categories (Chi square).

was lower in the middle category. There was a higher likelihood of frequent organic consumption in households where the participant and/or her partner were students, and in households with low income. The likelihood of frequent organic consumption was in fact inversely correlated with higher income (Table 3).

Participation in MoBa at later years (2005 or later) was associated with frequent use of organic food. This was also the case for those living in urban areas. When using a four-level variable for living area, based on traveling distance to nearest town or city, the largest share of women with frequent use of organic food was found in the most central areas $(9.4 \%)$, followed by the least central municipalities (8.6\%). The lowest prevalence of frequent organic consumption was in the middle-category municipalities $(8.0 \%$ and $8.4 \%$ in less or quite central municipalities respectively) (data not shown in table).

By combining the risk differences for the variables in the model we theoretically estimated that the group with the highest propensity to have a frequent intake of organic food were women $<20$ years of age, having BMI $<18.5$, adhering to a vegetarian diet, consuming alcohol and smoking occasionally during pregnancy, exercising three times a week or more, having attained less than 13 years of education, being a student and having a partner who is a student, having low household income (both the participant and her partner earned $<300000$ NOK), participating in MoBa in year 2007, and living in an urban area. The estimated prevalence of a frequent intake of organic food for this group was $61.8 \%$ (prevalence at reference category + risk difference for the relevant values of all the variables in the model). In the same way we estimated the prevalence in the group with the lowest propensity to have frequent intake of organic food to be $0.2 \%$.

\section{Discussion}

The main finding of this study was that no single "healthy lifestyle" orientation could be identified among the women who reported frequent use of organic food. The frequent use of organic food was associated with lower and higher age groups, lower BMI, a vegetarian diet, cigarette smoking and use of alcohol during pregnancy, regular exercise, lower and higher levels of education, the participant and/or her partner being a student, low household income, urban living area, and participation in MoBa between 2005 and 2007. The associations between socio-demographic and lifestyle variables and eating organic food reflect complexity and indicate that no quick label like "young and idealistic" or "well educated and wealthy" can be applied to describe women who report frequent intake of organic food during pregnancy. Some previous studies also reported that use of organic food is quite widely distributed across socio-economic groups and associated with various types of motivation $[10,29]$, while others, particularly within the marketing tradition, have identified consumer segments in the market with a high likelihood to buy organic food such as "the engaged", "the ecohealthy", or "the practical green" etc. [30].

The strength of this study is the large sample of pregnant women with participants from both urban and rural regions, representing all age groups and all socioeconomic groups. The participation rate in $\mathrm{MoBa}$ is $43 \%$ and the prevalence of organic consumption may not be representative for all pregnant women in Norway [26]. However, this is not likely to influence the associations between reported use of organic food and characteristics of the respondents. The potential bias due to self-selection in MoBa was recently evaluated by Nilsen et al., 2009 . No statistically relative differences in association measures were found between participants and the total 
population regarding eight exposure-outcome associations evaluated [31].

In the present study we examined the associations between participant characteristics and frequent organic consumption with and without women having missing data on participant characteristics. Covariates with missing data were BMI $(2.6 \%)$, exercise $(8.4 \%)$, education $(2.2 \%)$, income $(8.4 \%)$, and year of participation $(2.0 \%)$. The numbers of missing values were higher in year 2002 , in the youngest age group, among women with low education, among smokers, and among frequent organic food consumers. Including missing as separate categories in a regression is a simple method of dealing with missing values compared to the more correct but also more complex method of multiple imputations. Including missing in a regression will, contrary to popular belief, increase bias from confounding, but will reduce bias from possible heterogeneity of effects (interaction) between responders and non-responders/missing. It will also increase sample size and thereby power. The results from models with and without missing included were similar in our data, indicating that neither confounding nor heterogeneous effects played a strong role here.

The sum index provides a robust indicator of the consumption of a variety of the main organic food groups in the diet, appropriate for the explorative aim in this study. The sum index attributes equal importance to each food category and thus some detail may have been lost. The categories are dissimilar with regard to number of items within the category (e.g. 'eggs' containing only one item while 'fruit' and 'vegetables' contain numerous items). Eating 'mostly organic' vegetables is a more extensive practice than eating 'mostly organic' eggs. A related, but different challenge is that we do not know a respondents total variety of consumption within each category, e.g. whether 'mostly organic fruit' refers to only apples - or a whole range of different fruits. However, the high correlation between organic consumption within the six food groups supports the viability of using a sum index in this study (Table 2).

Eating a vegetarian diet was the characteristic which was most strongly associated with frequent consumption of organic food during pregnancy. Even though the total number of vegetarians among the MoBa-participants was low $(0.2 \%)$, this was the single most predictive factor among all variables in the analysis, with 23.1 percentage points higher prevalence of frequent organic use among vegetarians than among non-vegetarians (Table 3). This reinforces earlier findings of an association between eating organic food and a vegetarian diet [32,33]. Frequent use of organic food and eating a vegetarian diet may well be part of a healthy lifestyle, as a vegetarian diet has been associated with many health benefits such as lower risk of heart disease and type 2 diabetes [34-37]. Further associations between eating a vegetarian diet and the general dietary quality among the women with a frequent consumption of organic food will be published in a separate paper. Well-planned vegetarian diets are considered appropriate for individuals in all life-phases, including pregnancy [34]. Lower levels of BMI have been reported among vegetarians in various populations [35,37], and also among consumers of organic food in a study of soy consumers and non-soy consumers in Minnesota, USA [38].

Participation in regular exercise and being underweight or normal weight were also associated with being a frequent organic consumer. Being physically active is an important contributor to a healthy lifestyle in the general population as well as among pregnant women, and is strongly inversely related to excessive body mass [39-41].

Entering pregnancy with a normal weight is beneficial with regard to pregnancy complications and health outcomes for both the mother and the child. Maternal obesity is a risk factor for all major pregnancy complications, which have increased in prevalence in later years [42], including gestational diabetes, pre-eclampsia, foetal overgrowth, preterm births, and cesarean delivery [42-45]. Being underweight, on the other hand, is also associated with unfavorable birth outcomes such as preterm birth and low birth weight, while overall, the outcome is favorable and several adverse outcomes are less common in this group of women [46]. We plan to further investigate dietary habits among organic food consumers and to examine potential diet-health relationships related to organic food consumption during pregnancy. It would also be interesting to further investigate subgroups within the population, as the characteristics associated with frequent organic consumption in the present study have also been related to a higher prevalence of eating disorders, such as adhering to a vegetarian diet [47], exercising more than three times per week, older age and being a student [48].

It is well established that both cigarette smoking and alcohol consumption during pregnancy is associated with increased risk of adverse health outcomes for the fetus, and consequently health authorities in many countries, including Norway recommend that pregnant women and those trying for a baby should totally avoid alcohol and smoking [49]. In this study we found a higher prevalence of smokers among women with frequent consumption of organic food. If the use of organic food is motivated by perceived health benefits, this finding may appear surprising. However, sociological studies of health behavior have indicated that the associations between them are complex. In a Finish study, an attempt to construct 'health indices' based on all relevant factors associated with good health proved 
difficult, and even though there were clear associations between health behaviors, their distribution into different combinations were quite diverse [50,51]. Smoking has been shown to be central in the interplay between health behaviors, and the majority of smokers had either only smoked or had one additional unhealthy habit [51].

Our finding of a higher prevalence of cigarette smoking among women with a frequent consumption of organic food is contrary to a European multi-country study that reported less maternal smoking during pregnancy and current smoking in families with anthroposophic lifestyle (having children at Waldorf schools, eating organic/biodynamic food and/or living at farms practicing Biodynamic farming) compared to reference families [52,53], while a Swedish study reported equal prevalence of parental smoking in families with anthroposophic lifestyle vs. reference families [54]. In the present study, however, consumers of all types of organic food are included, and we have not looked at respondents adhering to an anthroposophic lifestyle in particular.

We found a two-sided trend between frequent use of organic food both in regard to age and education, with the highest and lowest age and education groups being more likely to be frequent organic consumers than the middle groups. Next to eating a vegetarian diet, being in the lowest age group $(<20$ years) represented the highest likelihood for being a frequent organic consumer, with 15.6 percentage points higher prevalence than in the reference group (30-34 years). The present study has a smaller age range than studies in the general population as only pregnant women were included. Studies in the general population have also reported diverging results related to age, some finding that younger age (see for example [55-58]) and others that older age [59] was associated with a higher propensity to buy organic food, while some reported no difference with regard to age [29]. It has been suggested that there may be a pattern whereby there are higher shares of younger consumers among early adopters in developing markets, while older consumers are in higher numbers in more mature markets [60]. In Denmark and Great Britain, both being mature markets for organic food, the highest likelihood of buying organic food was found in households with middle-aged. In Great Britain the likelihood was lower in both the younger and older groups, while in Denmark it generally increased with age, but with a peak for the age group 40-49 years [61]. The Norwegian market for organic food is not by far as mature as the British or Danish, even though it has developed quite rapidly during the last decade. It might be that we see a combination of young new-comers and women who have longer experience with eating organic food.

Household economy could be expected to be crucial for the level of organic consumption given the fact that these products generally are more expensive. However, our finding of an inverse relation between household income and frequency of organic consumption indicate a complexity beyond economic ability alone, and that other factors are more decisive for the likelihood of eating organic food. Higher levels of education, on the other hand, were associated with a higher likelihood of eating organic food compared with middle-levels of education, and so was being a student - even in the older age groups. Both education and income are strongly associated with better health in population studies. Our finding of lower household income may therefore be interpreted as an indicator of vulnerability with regard to health, while higher levels of education - particularly with increasing age, provides for robustness. The combination of higher education and lower income among the frequent consumers of organic food may point to a different value-orientation in this group.

Previous Norwegian surveys have reported higher levels of education among consumers with more frequent use of organic food and food produced without use of pesticides $[29,59,62]$, while a regional survey did not find any association between length of education and likelihood of buying organic food [63]. Studies from other countries have also reported differing results regarding respondents' level of education and use of organic food $[30,57,64,65]$. Higher income was associated with a higher likelihood of buying organic food in one Norwegian study [63], while no difference with regard to income was reported in another [29]. A study of consumption of organic food in Denmark and Great Britain reported an increased propensity to buy organic food with higher 'social group', a composite indicator of educational level and income. However, in both countries, the highest propensity to buy organic food was found for the middle class households, while it was actually lower for the upper middle class [61]. Another Danish study also found that income explained very little of the purchasing behavior related to organic food [30].

Taken together, the lifestyle- and socio-economic characteristics of the frequent organic food consumers in the present study point to a complex phenomenon, involving diverse groups of women which go beyond narrowly defined 'consumer segments'. Some of the characteristics, such as regular exercise, lower BMI, and - in part - higher education indicate robustness with regard to a healthy lifestyle, while other characteristics, such as cigarette smoking and use of alcohol, and - in part - lower levels of education, may indicate vulnerability with regard to health of mother and child.

Our finding of a higher prevalence of frequent organic users in urban areas, is contrary to previous Norwegian studies that reported no difference between urban and rural areas $[29,63]$, but in line with results from Denmark and Great Britain [60,66]. Further, our more 
nuanced finding that the highest level of organic consumption in the urban areas was followed by the most rural areas, with the lowest consumption in the two middle categories, is supported by other findings [67], and may be related to the possible 'idealistic' nature of organic consumption. Codron et al (2006) describe that a typical development for radical movements, such as those associated with organic food, is that when these products first enter the market, buyers are typically either local rural consumers, or urban consumers with higher income levels, including members of consumer associations and politically active movements sharing these values. In later phases, the constellations may change. These suggested lines of development may be relevant for Norway, where the market situation may still be described as not having reached maturity with regard to organic food - and we do find the highest levels of consumption among the contrasting groups: either urban or rural.

\section{Conclusions}

Our results indicated that frequent use of organic food is a practice that is adopted among pregnant women across various 'groups' referring to the personal, lifestyle and socio-demographic variables investigated. This fits well with earlier observations that the consumption of organic food in the general Norwegian population has not been limited to special sub-groups, but rather quite widely distributed across socio-economic groups.

We did find certain characteristics to be more common among the frequent organic food consumers, but these characteristics were diverse and not necessarily associated with a healthy lifestyle. Lower levels of education and income as well as smoking and use of alcohol in pregnancy were less favorable factors in relation to health in our cohort. On the other hand, being lean and doing regular exercise are in line with health recommendations. A vegetarian diet may well be part of a healthy lifestyle. In conclusion, we found that in our material associations between socio-demographic and lifestyle variables and eating organic food were complex and could not be reduced to one single 'healthy lifestyle' orientation. However, given the relatively short period of time that organic food has been available to the majority of people in Norway, patterns of organic food consumption may keep changing as the market grows more mature. Characteristics of pregnant women who eat organic food may then change, possibly making differences between socio-demographic groups and the association to the different lifestyle factors more easily discernable. A methodological implication of the results is that personal and socio-economic characteristics should be regarded as important covariates in future studies of potential health outcomes related to organic food consumption during pregnancy.

\section{Acknowledgements}

This project was supported by a grant from The Research Council of Norway, The Food Programme (project no. 176827). The Norwegian Mothe and Child Cohort Study is supported by the Norwegian Ministry of Health, NIH/NIEHS (grant no N01-ES-85433), NIH/NINDS (grant no.1 UO1 NS 04753701), and the Norwegian Research Council/FUGE (grant no. 151918/S10). We gratefully acknowledge Sesilje Elise Bondo Petersen and Sjurdur Frodi Olsen at The Danish National Birth Cohort for inspiring cooperation. Finally, we wish to thank the members of the MoBa Organic Food Reference Group for their generous and insightful support. The MoBa Organic Food Reference Group consists of Jan Alexander, Division of Environmental Medicine, The Norwegian Institute of Public Health, Oslo, Norway; Leiv S. Bakketeig, Division of Epidemiology, The Norwegian Institute of Public Health, Oslo, Norway; Jane A. Hoppin, The Epidemiology Branch of the National Institute of Environmental Health Sciences - National Institutes of Health, North Carolina, USA; Jon Magne Holten, Oikos - Organic Norway, Oslo, Norway; Katherine O'Doherty Jensen, Department of Human Nutrition, University of Copenhagen, Copenhagen, Denmark; Jackie Swartz,

Vidarkliniken, Järna, Sweden.

\section{Author details}

'Division of Environmental Medicine, Norwegian Institute of Public Health, Oslo, Norway. ${ }^{2}$ National Institute for Consumer Research (SIFO), Oslo, Norway. ${ }^{3}$ Department of Plant and Environmental Sciences, Norwegian University of Life Sciences, Ås, Norway. ${ }^{4}$ Division of Epidemiology, Norwegian Institute of Public Health, Oslo, Norway. ${ }^{5}$ Department of General Practice and Community Medicine, Faculty of Medicine, University of Oslo, Oslo, Norway.

\section{Authors' contributions}

HMM initiated and was PI of the study. HT and HMM designed the study. HT performed the statistical analysis assisted by HS, ALB and MH. HT wrote the manuscript. $A L B, G L, G R, M H$ and $G H O$ participated in the design of the study and contributed to the manuscript. All authors read and approved the final manuscript.

\section{Competing interests}

The authors declare that they have no competing interests.

Received: 7 July 2010 Accepted: 21 December 2010

Published: 21 December 2010

\section{References}

1. Godfrey KM, Barker DJ: Fetal programming and adult health. Public Health Nutr 2001, 4:611-24

2. Moore VM, Davies MJ: Diet during pregnancy, neonatal outcomes and later health. Reprod Fertil Dev 2005, 17:341-8.

3. Shapira N: Prenatal nutrition: a critical window of opportunity for mother and child. Womens Health (Lond Engl) 2008, 4:639-56.

4. Northstone K, Emmett PM, Rogers I: Dietary patterns in pregnancy and associations with nutrient intakes. Br J Nutr 2008, 99:406-15.

5. Brantsaeter $A L$, Haugen $M$, Samuelsen SO, Torjusen $H$, Trogstad $L$, Alexander J, Magnus P, Meltzer HM: A dietary pattern characterized by high intake of vegetables, fruits, and vegetable oils is associated with reduced risk of preeclampsia in nulliparous pregnant Norwegian women. J Nutr 2009, 139:1162-8.

6. Thompson JM, Wall C, Becroft DM, Robinson E, Wild CJ, Mitchell EA: Maternal dietary patterns in pregnancy and the association with smallfor-gestational-age infants. Br J Nutr 2010, 103:1665-73.

7. Debio: [http://www.debio.no/section.cfm?path=1,61]

8. Berg L: Tillitens triangler: om forbrukertillit og matsikkerhet [Report in Norwegian: Triangles of Trust. On consumer trust and food safety.] Professional Report no. 1-2005. Oslo: National Institute for Consumer research (SIFO); 2005

9. Shepherd R, Magnusson M, Sjoden PO: Determinants of consumer behavior related to organic foods. Ambio 2005, 34:352-9.

10. Torjusen $\mathrm{H}$, Kjærnes U, Sangstad L, O'Doherty Jensen K: European consumers' conceptions of organic food: a review of available research Professional report no. 4-2004. Oslo: National Institute for Consumer Research (SIFO); 2004.

11. Baker BP, Benbrook CM, Groth E, Lutz BK: Pesticide residues in conventional, integrated pest management (IPM)-grown and organic 
foods: insights from three US data sets. Food Addit Contam 2002, 19:427-46.

12. Lu C, Toepel K, lrish R, Fenske RA, Barr DB, Bravo R: Organic diets significantly lower children's dietary exposure to organophosphorus pesticides. Environ Health Perspect 2006, 114:260-3.

13. Bernhoft A, Clasen PE, Kristoffersen AB, Torp M: Less Fusarium infestation and mycotoxin contamination in organic than in conventional cereals. Food Addit Contam Part A Chem Anal Control Expo Risk Assess 2010, 27:842-52.

14. Bonde M, Sørensen JT: Effect of pig production systems and transport on the pathogen transfer risk into the food chain from Salmonella shed in pig faeces. Improving Sustainability in Organic and Low Input Food Production Systems. Proceedings of the 3rd International Congress of the European Integrated Project Quality Low Input Food (QLIF). University of Hohenheim, Germany, March 20-23 2007 Frick, CH: FiBL; 2007, 104-107.

15. Tamm L, Köpke U, Cohen Y, Leifert C: Development of strategies to improve quality and safety and reduce cost of production in organic 'low input' crop production systems. Improving Sustainability in Organic and Low Input Food Production Systems. Proceedings of the 3rd International Congress of the European Integrated Project Quality Low Input Food (QLIF). University of Hohenheim, Germany, March 20-23 2007 Frick, CH: FiBL; 2007, 104-107.

16. Brandt K, Mølgaard JP: Organic agriculture: does it enhance or reduce the nutritional value of plant foods? J Sci Food Agric 2001, 81:924-31.

17. Holmboe-Ottesen G: Increased levels of bioactive compounds in organically grown food plants. Possible health effects? In Bioactive compounds in plants - benefits for man and animals. Edited by: Bernhoft A. Oslo: Novus forlag; 2010:236-252[http://www.dnva.no/geomed].

18. Butler $G$, Collomb M, Rehberger B, Sanderson R, Eyre M, Leifert C. Conjugated linoleic acid isomer concentrations in milk from high- and low-input management dairy systems. J Sci Food Agric 2009, 89:697-705.

19. Rist L, Mueller A, Barthel C, Snijders B, Jansen M, Simoes-Wust AP, Huber M, Kummeling I, von Mandach U, Steinhart H, Thijs C: Influence of organic diet on the amount of conjugated linoleic acids in breast milk of lactating women in the Netherlands. Br J Nutr 2007, 97:735-43.

20. Dangour AD, Dodhia SK, Hayter A, Allen E, Lock K, Uauy R: Nutritional quality of organic foods: a systematic review. Am J Clin Nutr 2009, 90:680-5.

21. Dangour AD, Lock K, Hayter A, Aikenhead A, Allen E, Uauy R: Nutritionrelated health effects of organic foods: a systematic review. Am J Clin Nutr 2010, 92:203-10.

22. Benbrook C, Davis DR, Andrews PK: Methodologic flaws in selecting studies and comparing nutrient concentrations led Dangour et al to miss the emerging forest amid the trees. Am J Clin Nutr 2009, 90:1700-1.

23. Hamm U, Gronefeld F, Hamm U, Gronefeld F: The European market for organic food: revised and updated analysis. University of Wales Aberystwyth (School of Management and Business); 2004.

24. Terragni L, Torjusen $H$, Vitters $\varnothing$ G: The dynamics of alternative food consumption: contexts, opportunities and transformations. Anthropology of food [Webjournal], S5 2009 [http://aof.revues.org/index6400.html].

25. Norwegian Agricultural Authority: Produksjon og omsetning av økologiske landbruksvarer. Rapport for 2009. [Report in Norwegian: Production and sales of organic products. Report for 2009.] Oslo: Norwegian Agricultural Authority; 2010.

26. Magnus P, Irgens LM, Haug K, Nystad W, Skjaerven R, Stoltenberg C: Cohort profile: the Norwegian Mother and Child Cohort Study (MoBa). Int $J$ Epidemiol 2006, 35:1146-50

27. Meltzer HM, Brantsaeter AL, Ydersbond TA, Alexander J, Haugen M: Methodological challenges when monitoring the diet of pregnant women in a large study: experiences from the Norwegian Mother and Child Cohort Study (MoBa). Matern Child Nutr 2008, 4:14-27.

28. Statistics Norway: Defining geographic location of a municipality in relation to urban settlements of various sizes. [http://www3.ssb.no/ stabas/ltemsFrames.asp?

$\mid \mathrm{D}=5285601$ \&Language $=$ en\&VersionLevel=classversion\& MenuChoice=Language], (Accessed Sept 2009).

29. Storstad O, Bjørkhaug $\mathrm{H}$ : Foundations of production and consumption of organic food in Norway: Common attitudes among farmers and consumers? Agriculture and Human Values 2003, 20:151-63.

30. Beckmann SC, Brokmose S, Lind RL: Danske forbrugere og økologiske fødevarer. [Report in Danish: Danish consumers and organic foods] Copenhagen: Copenhagen Business School; 2001.
31. Nilsen RM, Vollset SE, Gjessing HK, Skjaerven R, Melve KK, Schreuder P, Alsaker ER, Haug K, Daltveit AK, Magnus P: Self-selection and bias in a large prospective pregnancy cohort in Norway. Paediatr Perinat Epidemiol 2009, 23:597-608.

32. Holt GC: "Ecological eating", food ideology and food choice. An analysis of the changing British diet with reference to the consumption of meat and organically produced food Food Policy Research Unit, Department of Biomedical Sciences, University of Bradford, UK; 1993

33. Torjusen H, Nyberg A, Wandel M: Økologisk produsert mat: Forbrukernes vurderinger og bruksmønster [Report in Norwegian: Organic food: consumers perceptions and dietary choices] Professional Report no. 5-1999. Oslo: National Institute for Consumer Research (SIFO); 1999.

34. American Dietetic Association: Position of the American Dietetic Association: Vegetarian Diets. Journal of the American Dietetic Association 2009, 109:1266-82

35. Key TJ, Appleby PN, Rosell MS: Health effects of vegetarian and vegan diets. Proc Nutr Soc 2006, 65:35-41.

36. Key TJ, Appleby PN, Spencer EA, Travis RC, Roddam AW, Allen NE: Cancer incidence in vegetarians: results from the European Prospective Investigation into Cancer and Nutrition (EPIC-Oxford). Am J Clin Nutr 2009, 89:1620S-1626.

37. Tonstad S, Butler T, Yan R, Fraser GE: Type of vegetarian diet, body weight, and prevalence of type 2 diabetes. Diabetes Care 2009, 32:791-6.

38. Schryver T, Smith C, Wall M: Self-identities and BMI of Minnesotan soy consumers and non-consumers. Obesity 2007, 15:1101-6.

39. Brooks GA, Butte NF, Rand WM, Flatt JP, Caballero B: Chronicle of the Institute of Medicine physical activity recommendation: how a physical activity recommendation came to be among dietary recommendations. Am J Clin Nutr 2004, 79:921S-30S.

40. ACOG Committee on Obstetric Practice: Committee opinion \#267: exercise during pregnancy and the postpartum period. Obstetrics \& Gynecology 2002, 99:171-3.

41. Royal College of Obstetricians and Gynecologists: Exercise in pregnancy. Statement no 42006 [http://www.rcog.org.uk/womens-health/clinicalguidance/exercise-pregnancy].

42. Siega-Riz AM, Viswanathan M, Moos MK, Deierlein A, Mumford S, Knaack J, Thieda P, Lux L, Lohr KN: A systematic review of outcomes of maternal weight gain according to the Institute of Medicine recommendations: birthweight, fetal growth, and postpartum weight retention. Am J Obstet Gynecol 2009, 201:339-14.

43. Kramer MS, Morin I, Yang H, Platt RW, Usher R, McNamara H, Joseph KS, Wen SW: Why are babies getting bigger? Temporal trends in fetal growth and its determinants. J Pediatr 2002, 141:538-42.

44. Bhattacharya S, Campbell DM, Liston WA, Bhattacharya S: Effect of Body Mass Index on pregnancy outcomes in nulliparous women delivering singleton babies. BMC Public Health 2007, 7:168.

45. Jansson N, Nilsfelt A, Gellerstedt M, Wennergren M, Rossander-Hulthen L, Powell TL, Jansson T: Maternal hormones linking maternal body mass index and dietary intake to birth weight. Am J Clin Nutr 2008, 87:1743-9.

46. Sebire NJ, Jolly M, Harris J, Regan L, Robinson S: Is maternal underweight really a risk factor for adverse pregnancy outcome? A population-based study in London. BJOG 2001, 108:61-6.

47. Aloufy A, Latzer Y: Diet or health-the linkage between vegetarianism and anorexia nervosa. Harefuah 2006, 145:526-31-549.

48. Juhl M, Madsen M, Andersen AM, Andersen PK, Olsen J: Distribution and predictors of exercise habits among pregnant women in the Danish National Birth Cohort. Scand J Med Sci Sports 2010.

49. Norwegian Directorate of Health: A national clinical guideline for antenatal care. Short version - recommendations. Nasjonale retningslinjer for svangerskapsomsorgen (in Norwegian) 2006, 13-4.

50. Luoto R, Prattala R, Uutela A, Puska P: Impact of unhealthy behaviors on cardiovascular mortality in Finland, 1978-1993. Prev Med 1998, 27:93-100

51. Laaksonen M, Prattala R, Lahelma E: Sociodemographic determinants of multiple unhealthy behaviours. Scand J Public Health 2003, 31:37-43.

52. Alfven $T$, Braun-Fahrlander C, Brunekreef B, von Mutius E, Riedler J, Scheynius A, van Hage M, Wickman M, Benz MR, Budde J, Michels KB, Schram D, Ublagger E, Waser M, Pershagen G, PARSIFAL study group: Allergic diseases and atopic sensitization in children related to farming and anthroposophic lifestyle-the PARSIFAL study. Allergy 2006, 61:414-21.

53. Floistrup H, Swartz J, Bergstrom A, Alm JS, Scheynius A, van Hage M, Waser M, Braun-Fahrlander C, Schram-Bijkerk D, Huber M, Zutavern A, von 
Mutius E, Ublagger E, Riedler J, Michaels KB, Pershagen G, Parsifal Study Group: Allergic disease and sensitization in Steiner school children. $J$ Allergy Clin Immunol 2006, 117:59-66.

54. Alm JS, Swartz J, Lilja G, Scheynius A, Pershagen G: Atopy in children of families with an anthroposophic lifestyle. Lancet 1999, 353:1485-8.

55. Grunert SC, Kristensen K: Den danske forbruger og økologiske fødevarer. [Report in Danish: The Danish Consumer and Organic Food]. Working paper, Series H no. 62 The Aarhus School of Business. Department of Information Science, Aarhus; 1992

56. Infood: Forbrugernotat. [Report in Danish: Consumer report] 1997 [http:// www.ecoweb.dk/infood/not9708.htm].

57. Ott SL: Supermarket shoppers' pesticide concerns and willingness to purchase certified pesticide residue-free fresh produce. Agribusiness 1990, 6:593-602.

58. Jolly DA: Differences between buyers and nonbuyers of organic produce and willingness to pay organic price premium. Journal of Agribusiness 1991, 9:97-111.

59. Bugge A, Wandel M: Forbrukerholdninger til moderne matvareproduksjon. Landbruksøkonomisk forum 1995, 12:15-25.

60. O'Doherty Jensen K, Larsen HN, Mølgaard JP, Andersen J-O, Tingstad A, Marckmann P, Astrup A: Økologiske fødevarer og menneskets sundhed. Rapport fra vidensyntese udført i regi af Forskningsinstitut for Human Ernæring, KVL. [Report in Danish: Organic foods and Human Health.] Foulum: Danish Research Centre for Organic Farming; 2001.

61. Wier M, O'Doherty Jensen K, Andersen LM, Millock K: The character of demand in mature organic food markets: Great Britain and Denmark compared. Food Policy 2008, 33:406-21.

62. Torjusen $\mathrm{H}$ : Økologisk mat. Hindringer og muligheter for forbruk av økologisk mat sett fra forbrukernes side [Report in Norwegian: Obstacles and possibilities to organic food consumption in Norway] Project Report no. 16-2001. Oslo: National Institute for Consumer Research (SIFO); 2001.

63. Torjusen $\mathrm{H}$, Lieblein $\mathrm{G}$, Wandel M, Francis CA: Food system orientation and quality perception among consumers and producers of organic food in Hedmark County, Norway. Food Quality and Preference 2001, 12:207-16

64. Huang $\mathrm{CL}$ : Consumer preferences and attitudes towards organically grown produce. European Review of Agricultural Economics 1996, 23:331-42.

65. Byrne PJ, Toensmeyer UC, German CL, Muller HR: Analysis of consumer attitudes toward organic produce and purchase likelihood. Journal of Food Distribution Research 1991, 22:49-62.

66. Wier M, Andersen LM: Consumer demand for organic foods: Attitudes, values and purchasing behaviour. DARCOFenews 2003 [http://orgprints. org/1829/1/darcof.pdf].

67. Codron $J M$, Siriex $L$, Reardon $T$ : Social and environmental attributes of food products in an emerging mass market: Challenges of signaling and consumer perception, with European illustrations. Agriculture and Human Values 2006, 23:283-97.

\section{Pre-publication history}

The pre-publication history for this paper can be accessed here: http://www.biomedcentral.com/1471-2458/10/775/prepub

doi:10.1186/1471-2458-10-775

Cite this article as: Torjusen et al:: Characteristics associated with organic food consumption during pregnancy; data from a large cohort of pregnant women in Norway. BMC Public Health 2010 10:775.

\section{Submit your next manuscript to BioMed Central and take full advantage of:}

- Convenient online submission

- Thorough peer review

- No space constraints or color figure charges

- Immediate publication on acceptance

- Inclusion in PubMed, CAS, Scopus and Google Scholar

- Research which is freely available for redistribution

Submit your manuscript at www.biomedcentral.com/submit
Biomed Central 